\title{
Exploration of the Important Five Factors of Personality Traits and Attitude of the 9th and 10th Grade Students towards the Subject of Chemistry
}

\author{
Tayyaba Muhammad Akram¹, Fatima Javed ${ }^{1}$, Sumaira Majeed ${ }^{1}$, Hamid Ikram², Anam Ilyas ${ }^{1}$, \\ Aisha Sami ${ }^{1}$ \\ ${ }^{1}$ Department of Science Education, Institute of Education and Research (IER), University of \\ the Punjab, Lahore, Pakistan \\ ${ }^{2}$ Department of Education, Government College University, Faisalabad, Pakistan
}

\begin{abstract}
Personality is an important feature in development of students' attitude towards Chemistry. The basic aim of this research was to explore the relationship among personality traits and students' attitude towards the course of Chemistry. Results found in this research work also determine the effect of gender and class on students' personality along with affective traits of attitude. The sample size was consisting of 780 secondary school (male and female) students. Valid and reliable instrument was developed. Data was analyzed through correlation and t-test. It is concluded that there is considerable mean effect of demographic variables on students' personality and attitude. Whereas $t$-test revealed that gender (male and female students) as well as class (9th and 10th grade students) showed significant difference in affective characteristics of attitude and effect of personality traits towards the chemistry course. Results and findings in this research paper is useful and significant for parents, teachers, curriculum developers and educators in order to reform, plan and design curriculum and teaching methodologies according to the requirement of the modern world.
\end{abstract}

\section{Introduction}

Science and technology plays an essential role in advancement of any national economy. The developed countries have already familiar with the significance of chemistry course in their national economy. Research evidences have shown that chemistry has strong influence on quality of life and nation building. Any nation aiming to be systematically and technically established must have suitable level of chemistry tutoring [1]. These lead chemists in 2008 to declare "what on earth is not chemistry". To develop a positive attitude of students towards chemistry is the major responsibility of science educators. Personality plays an important role in determining students' attitude towards chemistry.

Personality is a set of persistent and distinctive arrangement of judgments, approaches and behavior that makes persons different from each other. Personality describes in what way persons behave and recognize themselves and their surrounding environment. Personality not only effects the way of reacting in our surroundings but also forecast to act in definite ways. Personality is a composite set of actions of understandings and procedures that provides plan, trend and way to the person's life [2].

In the present era, chemistry is the most demanding area for the betterment of any country. However, chemistry is considered to be a very dry subject by the students. The students do not have positive attitude towards chemistry. Pakistan is a developing country and we have very less number of engineers and doctors as compared to developed countries. To ensure the influx of new scientists, it is important to view how science is taught in schools and how this approach affects student's willingness to take an active role in their chemistry learning. Research has consistently shown attitudes as an important component of chemistry education impacting not only learners' participation and interest but also their achievement in chemistry [6]. It is also reported in research findings that a high correlation between positive attitude towards chemistry [10].

The research on attitudes toward chemistry depicts interest, participation, self-efficacy, and achievement. So, it is essential to conduct a research on attitudes of students towards chemistry. The prior researches did not consider interaction of personality traits and attitudes toward chemistry. It is significant to analyse these two arenas because different researches have shown discrete results. In this research the researchers are interested in the exploration of the personality traits and attitude towards chemistry. This study is designed to explore the personality traits and attitude of the students towards chemistry.

\section{Enormous Five Important Personality Attributes}

Personality is related to that attribute of a person which have steady outline of emotions, thoughts and 
behaviour. Some people are anxious, risk taker, highly-strong, confident, shy and quiet.

The five-factor model of personality is asset of group of personality attributes in relations of five elementary proportions. A comprehensively used personality model, McCrae and Costa's [3] NEO Five Factor Model, or "Big Five Model", comprised of the subsequent personality components:

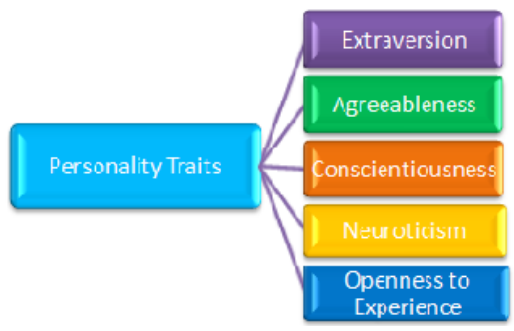

Figure1. The 'Big Five' Factors Personality Model

The first important component of the personality trait that has immense effect is Extraversion which leads to the tendency to be socially active, fun-loving, talkative, assertive, out-going and positive to take group leadership positions and expertise cheering effects such as liveliness, enthusiasm and eagerness. The second important component is of the personality trait is Agreeableness, it is defined as the trend to be kind, helpful, trusting, accommodating, loving, and gentle while persons with little friendliness are despicable, distrustful, and irritated. The third component is Conscientiousness, it is the tendency to be Hardworking, Motivated, well organized, dutiful, self-discipline and achievementoriented. People with low conscientiousness are relaxed, impulsive, and careless. Fourth component is Neuroticism, it is the trend to experience humble expressive modification and knowledge of undesirable feelings such as nervousness, self-doubt, and aggression. The final component is Openness to experience, this is the tendency to accept different concepts and also reveals originality, thoughts, and open-mindedness." Directness to experiences leads to curiosity about an individual inner and outer world [4].

\section{Approach}

Approach is some of the further most influential concept in terms of societal mindset [5]. Approach can be well-defined in the form of emotional state that individual possess about an entity, built on his or her experience, understanding and certainty. This explanation is established on the model that approach comprised of the three constituents of cognition, affect, and behavior [6]. Societal psychologists have also extended viewed approach as having three constituents (see Figure 2):

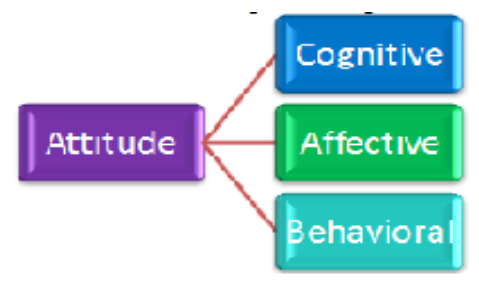

Figure 2. Theoretical Structure for Approach

The cognitive constituent is the set of theories about the traits of the approaches. The Behavioral component relate to the manner person act toward the situation. The Affective constituent comprised of frame of mind about situation i.e., the opinions and feelings any one has toward an approach object such as chemistry lab, chemistry instructions and chemistry course are discussed as important point of view. We can say "Affect" indicates how persons feel and think about the situation (both moral and immoral approaches), as it can be conveyed by biological action or statement.

Affective features are very far significant as cognitive variables in effecting learning consequences, professional varieties and use of relaxation stage [7]. Affective features included in this reading are (see Figure 3):

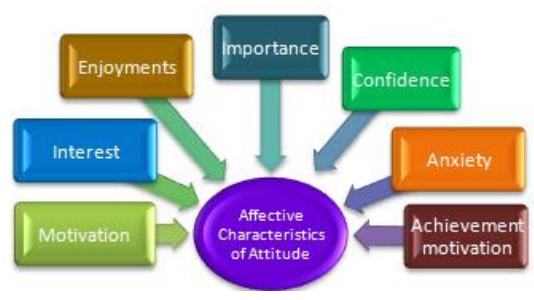

Figure 3.

Figure 3. Agenda of Affective features of Approach

According to ligature interest is a very precise form of approach. When we are involved in a specific occurrence or action, we show favour and interest to study specific subject and provide time to it [8].

Gredler, Broussard and Garrison defined inspiration as "the quality that changes us to do or not to do something" [9]. Turner explained inspiration as mental commitment, which is defined as "intentional usage of advanced self-regulated learning approaches, such as giving responses, association, preparation, and observing" [10]. More over anxiety is the feeling of tension, uneasiness, nervousness, and worry, whereas, 'Pleasure is an excitement that is about how we feel, not about what we think'. Psychologists have well-defined pleasure as an emotional state of desire. Pleasure of 
chemistry, physics or biology was related with sex differences in utmost of the studies [11]. It is found that girls enjoy natural sciences and males enjoy corporal sciences. Chemistry and physics as the least pleasant focuses. According to Katarina Salta [13], the mainstream of pupils diagnoses that chemistry understanding is beneficial to understand phases of their daily life, but only $4 \%$ of pupils show their desire to carry on chemistry studies.

Success inspiration has been well-defined as the degree to which persons vary in their requirement to struggle, to achieve rewards, such as physical pleasure, applause from others and approaches of distinct mastery [12], [13].

\section{Literature Review}

In this research the researchers are interested in the exploration of the personality traits and attitude towards chemistry. Here we will give a brief review to know the impact of personality and attitude towards chemistry.

\section{Significance of the Study}

In development and implementation of curricula and instructional performance the considering of Personality is an important criterion in determining student attitude towards chemistry. Current research work would be beneficial for curriculum designers and classroom teachers to apply relevant approaches for enhancing meaningful chemistry learning. It also supports to develop positive attitude towards chemistry. Therefore, the knowledge of students' personality and attitude would be supportive equally in academic and career counselling.

\section{Methodology}

\subsection{Research Questions}

The research answered following questions:

(1) if there is relationship exists between students' personality and attitude in chemistry;

(2) if there is any significant effect of different demographic variables on students' personality and attitude.

\subsection{Research Design}

5.2.1 Sampling. The accessible population for the study contained chemistry students from secondary schools in Lahore city, Pakistan. O-levels chemistry students were excluded. 780 chemistry students selected through stratified random sampling technique as a sample size for the research. Further distribution of the sample is shown in Figure 4.

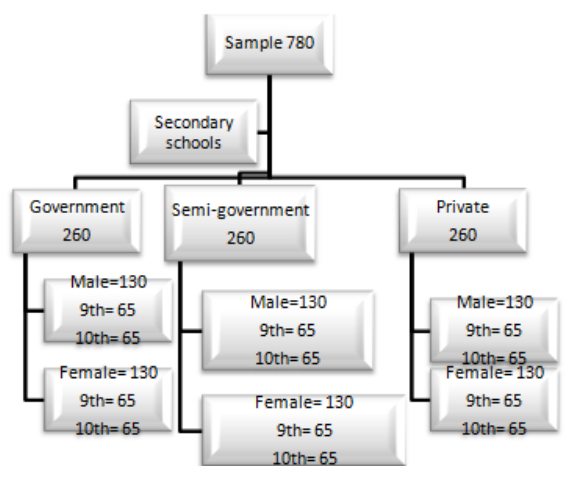

Figure 4. Distribution of sample from three sectors (government, semi-government and Private), N=780

\section{Development and Validation of Instrument}

To achieve the objective of the study, researcher constructed a questionnaire comprised on 37 statements. With the expert opinion constructed questionnaire is validated and to measure the consistency of the tool pilot study was conducted to ensure the reliability by 0.84 Cronbach's alpha value. The students had to respond by expressing their level of agreement on a five-point Likert scale. The questionnaire includes six demographic variables (gender, age, class, choice of course, family type, parents' qualification) and two factors.

\section{Data Analysis and Findings}

The data was analysed through the mean, correlation and t-test.

\subsection{Data Analyses}

Response was analysed through mean values and correlation test.

Table 1 illustrates that there is a strong relationship between openness to experience and interest, Motivation, Enjoyment, importance, confidence and attitude. There is also a strong relationship between personality with motivation, Anxiety", "Confidence" and "Attitude". Whereas, there was a weak or no correlation found between rest of the factors of "personality Traits" and subfactors of "Attitude".

Table 2 indicates that there is a significant mean difference of perception about factors and subfactors between the male and female students towards Chemistry course at secondary school level. 
Table 1. Correlation between sub-factors of personality trade and attitude

\begin{tabular}{|l|c|c|}
\hline $\begin{array}{l}\text { Correlation between factors of } \\
\text { "Personality Traits" and "Attitude" }\end{array}$ & r-value & Sig. \\
\hline $\begin{array}{l}\text { 1. Correlation between "Openness } \\
\text { To Experience" and }\end{array}$ & & 0.000 \\
\hline i. Interest & 0.699 & 0.000 \\
\hline ii. Motivation & 0.797 & 0.000 \\
\hline iii. Enjoyment & 0.529 & 0.000 \\
\hline iv. Importance & 0.608 & 0.000 \\
\hline v. Confidence & 0.793 & 0.000 \\
\hline vi. Attitude & 0.755 & \\
\hline 2. Correlation between & & 0.000 \\
\hline "Personality and & & 0.000 \\
\hline i. Motivation & 0.537 & 0.000 \\
\hline ii. Anxiety & 0.501 & 0.000 \\
\hline iii. Achievement Motivation & 0.420 & 0.000 \\
\hline iv. Confidence & 0.619 & \\
\hline v. Attitude & 0.677 & \\
\hline
\end{tabular}

Note: $\mathrm{p} \leq 0.001, * r$-value $(\mathrm{p}=$ Sig. value $)$

Table 2. Effect of gender (male and female) on Factors and Sub-Factors $\mathrm{p} \leq 0.05$

\begin{tabular}{|l|c|c|c|c|c|}
\hline Factors & \multicolumn{2}{|c|}{ Mean values } & Df & t-value & Sig. \\
\hline & Male & Female & & & \\
\hline i. Personality & 3.58 & 3.65 & 765.78 & 2.24 & 0.020 \\
\hline ii. Attitude & 3.56 & 3.44 & 778.00 & 2.87 & 0.004 \\
\hline Sub-factors & & & & & \\
\hline i. Extraversion & 3.82 & 4.05 & 751.19 & 5.07 & 0.000 \\
\hline ii. Agreeableness & 3.76 & 3.96 & 778.00 & 4.22 & 0.000 \\
\hline iii. Conscientiousness & 3.85 & 4.01 & 768.91 & 3.55 & 0.000 \\
\hline iv. Interest & 3.48 & 3.27 & 760.25 & 3.42 & 0.001 \\
\hline v. Enjoyment & 3.53 & 3.26 & 752.30 & 3.73 & 0.000 \\
\hline vi. Achievement Motivation & 3.58 & 3.32 & 778.00 & 4.40 & 0.000 \\
\hline
\end{tabular}

Table 3. Effect of grade (Male, Female) on Factors

\begin{tabular}{|l|c|c|c|c|c|}
\hline Factors & \multicolumn{2}{|c|}{ Mean values } & Df & t-value & Sig. \\
\hline & $9^{\text {th }}$ & $10^{\text {th }}$ & & & \\
\hline i. Personality & 3.56 & 3.66 & 778 & 3.258 & 0.001 \\
\hline ii. Attitude & 3.45 & 3.54 & 778 & 2.241 & 0.025 \\
\hline Sub-factors & & & & & \\
\hline i. Extraversion & 3.80 & 4.07 & 757.08 & 5.96 & 0.000 \\
\hline ii. Agreeableness & 3.78 & 3.94 & 778.00 & 3.11 & 0.002 \\
\hline iii. Importance & 3.65 & 3.90 & 778 & 4.72 & 0.000 \\
\hline
\end{tabular}


Results showed in Table 2 indicate that mean difference of perception between male and female students with i) factor Personality, t-value (2.237) $\mathrm{p}<0.05$, ii) with factor "Attitude" at secondary school level with t-value (2.871) $\mathrm{p}<0.05$ is significant. Similarly, there is a mean difference between the perception of male and female students with iii) subfactor Extraversion with t-value (5.070) $\mathrm{p}<0.05$, iv) with sub-factor Agreeableness at secondary school level as t-value (4.220) p<0.05, v) with Conscientiousness t-value $(3.550) \mathrm{p}<0.05$, vi) with Interest, t-value $(3.420) \mathrm{p}<0.05$, vii) with Enjoyment, t-value (3.730) $\mathrm{p}<0.05$, and vi) with Achievement Motivation t-value (4.40) ) $\mathrm{p}<0.05$ is significant.

Table 3 indicates that there is a significant mean difference of perception about factors and subfactors between the $9^{\text {th }}$ and $10^{\text {th }}$ class students.

Results showed in Table 3 indicate that there is a considerable mean difference of perception different class students with i) factor Personality, t-value (3.258) $\mathrm{p}<0.05$, ii) with factor "Attitude" at secondary school level with t-value $(2.241) \mathrm{p}<0.05$. Likewise, there is a noteworthy mean difference among the perception of male and female students with iii) sub-factor Extraversion with t-value (5.96) $\mathrm{p}<0.05$, iv) with sub-factor Agreeableness at secondary school level as t-value $(3.11) \mathrm{p}<0.05$, vi) with Importance, t-value (4.72) $\mathrm{p}<0.05$ towards Chemistry course at secondary school level.

\section{Discussion}

In this research work we studied and analysed the relationship among personality traits and attitudes. The effect of gender and 9th and 10th class perception on personality and chemistry course related attitudes of secondary school students (see Table 1, 2 and 3) is also studied.

In this study researchers found the Correlation $r-$ value shows significant strong positive relationship between "Openness to Experience" with Interest, Motivation, Enjoyment, Importance, Confidence, Attitude. Similarly, strong correlation between "Personality traits" with Motivation, Anxiety, Confidence and Attitude.

While the previous research [16] reveals that attitudes of students to science exhibit positive relationship with Agreeableness, Extra-version, Openness, and Conscientiousness toward science.

Researchers found through t-test that the significant mean difference exist between Gender (male and female) and Extraversion, Agreeableness, Conscientiousness, Personality, Interest, Enjoyment, Achievement Motivation and Attitude at secondary school level towards the subject of chemistry (see Table 2 and 3).

The results found in this study reveals that the significant mean difference between Class (9th and 10th grade) and, Personality (factor), Attitude (factor), Extraversion (sub-factor), Agreeableness (sub-factor), Importance (sub-factor) towards Chemistry at secondary school level (see Table 3) while the previous research reveals that students' attitudes is rarely studies by chemistry educators. A decline in the attitude toward the course of chemistry was also found in present research [14].

The results of the study suggest that teachers should consider all the three learning domains which would lead to improve interests and motivation to learn chemistry. The result shows that it is very important for the teachers to employ studentcentered approaches to tackle the attitudes of learners and endorse learners' motivation in chemistry.

\section{Conclusions, Recommendations and Future study}

The results in this research work reveal that personality has positive control on development of students' Attitude towards chemistry. This research could be able to remind chemistry teachers to give more concentration to students' attitudes toward chemistry and personality traits, which might play a meaningful role in chemistry education. It is recommended that chemistry teachers work to provide more personal autonomy in chemistry, because of its power and the consensus that chemistry offers little space for the pupils as an autonomous intellectual agent. Students wish for more opportunities in chemistry for practical work, extended investigations, and open discussion.

The findings emphasize the need for understanding of different personality traits possessed by chemistry students and that all negative outlooks about the subject should be altered. Results in this study also show that demographic variables have significant effect on students' personality and attitude towards chemistry.

The recommendations drawn on the basis of the findings are stated below:

The information about students' personality and attitude will help Chemistry teachers to use different mediums of instruction which suits to students' personality that can also help to develop more positive attitude to learn the subject of chemistry as different students have different preferences for different instructional techniques. Some students prefer student-centred instructional techniques whereas others prefer teacher-centred instructional methods.

School career counselors should be made to organize regular career guidance to students and this in turn, will make the students know the need or importance of chemistry to their profession, or in furthering their education.

Students must be provided all the equipment while working in the Chemistry lab. All the 
experimental tasks should be related with the daily life.

Parent and teacher meeting should be held on regular basis and parents should give freedom to their children to choose the course in which they have interest. Parents, teachers should be aware of students' differences in personalities this will help parents and teachers to guide students for choosing subjects that suits to one's personality.

Chemistry teachers should be given positive reinforcement to students who make efforts in chemistry work. This will make other students put more efforts in learning chemistry.

In order to excel in this era, it is vital to cater students' attitudes during the teaching. More researches should be done in this field. The practical nature of chemistry should be emphasized while teaching. The student centred techniques will stimulate the interest of the students. More chemistry related extra-curricular activities should be organized for the students this will enhance the development of positive of positive attitude towards chemistry [15].

\section{References}

[1] Eke, G.E. "Regulatory Mechanism for sound chemicals Management". A paper presented at the 1 st mandatory training workshop of ICCON in Lagos, Nigeria, 2008.

[2] Pervin, L. A., "The Science of personality", European Journal of Personality, 1997, 11(3), pp 245-247.

[3] Barrick, M. R., Mount, M. K., \& Judge, T. A., "Personality and performance at the beginning of the new millennium: What do you know and where do we go next?", International Journal of Selection and Assessment,2001, 9, p. 9-30.

[5] Zanna, M. P., \& Rempel, J. K., “Attitudes: A new look at an old concept". In D. Bar-Tal \& A. W. Kruglanski (Eds.), The social psychology of knowledge. New York: Cambridge University Press, 1988.

[6] Ajda, K., "Assessing high school students' attitudes toward chemistry with a shortened semantic differential", Chem. Educ. Res. Pract., 2015,16, pp. 283-292.

[7] Koballa, T. R., (1988). "Attitude and Related Concepts in Science Education", Science Education., 1988, 72(2), 115-126

[8] Gardner, P. and Tamir, P. "Interest in Biology. Part I: A multidimensional construct". Journal of
Research in Science Teaching, 1989, 26, pp. 409423.

[9] Rizwan, A. R., M. Nasir and R. Norman, "Motivation and Science Perforamnce: Influence on Student Learning In Science", Science International, 2015, 27(2), pp.1445-1452.

[10] Turner, J. C. "The influence of classroom contexts on young children's motivation for literacy". Reading Research Quarterly, 1995, 30(3), 410-441.

[11] Kenya, D., Korir, K., "The Influence of Students' Attitude towards Gender Role Stereotypes on their Performance in Mathematics and Chemistry in Secondary Schools in Bomet District", International Journal of Humanities and Social Science, 2014, 4, 8(1), pp. 252.

[12] Stables, A., "Differences between pupils from mixed and single-sex schools in their enjoyment of school subjects and in their attitudes to science and to school". Educational Review,1990, 42, 221-230.

[13] Salta, K., \& Tzougraki, C. "Attitudes toward chemistry among 11th grade students in high schools in Greece". Science Education, 88(4), pp.535-547.

[14] McClelland, D. C. Human motivation. Chicago:Scott Foresman, 1985.

[15] Zuway-R, H. and Huann-shyang, L., "An Investigation of Students' Personality Traits and Attitudes toward Science", International Journal of Science Education, 2011, 33(7), pp. 1001-1028.

[16] Hasan, O. E. (1985). "An investigation into factors affecting attitudes toward science of secondary school students in Jordan". Science Education, 1985, 69(1), 1-18. 